\title{
Bidding farewell to 2020: what lessons have we learned and what can bioethics continue to teach us?
}

\author{
Graeme T. Laurie ${ }^{1}$
}

Received: 13 October 2020 / Revised: 13 October 2020 / Accepted: 13 October 2020 / Published online: 20 November 2020

(C) National University of Singapore and Springer Nature Singapore Pte Ltd. 2020

For too many of us, 2020 will go down as the worst year in living memory. As the year comes to an end, the COVID-19 pandemic seems to be entering a second wave in many corners of the globe; apparent successes in getting the virus under control are too few and too early to call; lockdowns — both local and national — are being re-imposed with increasing frequency; and long-standing social injustices such as poverty, discrimination, domestic abuse and inadequate healthcare provision have been more fully exposed and significantly exacerbated in this closing year of the second decade of the millennium. But it is precisely for these reasons that bioethical contributions are required now more than ever before. In the same way that 2020 has taught us that science and politics cannot be divorced from each other, nor can ethics be excluded from the debates about robust and effective social responses to a global threat that reaches into the lives of each and every one of us. Indeed, the importance of recognizing the interconnectedness of both responses and failures in the COVID-19 pandemic to wider social and ethical issues has never been greater. The collective contributions to this December issue of the Asian Bioethics Review demonstrate this all too clearly.

The original articles in this volume illustrated the theme of interconnectedness rather well. Than et al. (2020) offer empirical insights to the levels of awareness among medical postgraduate students in Myanmar towards research ethics and research ethics committees (RECs) in delivering scientifically sound, ethically robust research. Their findings provide strong evidence that far more training is required on the centrally important role of RECs and research ethics more generally, and arguably, this call has all the more force in times of emergency when timely and efficient ethics review must work to support expedited scientific responses. The theme of efficiency and effectiveness is continued by Ooi (2020) in the context of overtreatment in the clinical setting, warning of the vagaries of factors that drive a tendency towards overtreatment in modern healthcare systems; once again, lessons here are particularly poignant when already-stretched services are put under further strain by a public health emergency.

Graeme T. Laurie

Graeme.Laurie@ed.ac.uk

1 Edinburgh Law School, The University of Edinburgh, Edinburgh, UK 
The twin objectives to emerge are those of the efficient and just use of scarce resources while ensuring that there is not unjust diversion of resources away from existing needs towards emergency demands on care. Turning to the economic dimensions of healthcare provision, Wong (2020) uses the example of a healthcare overpricing scandal in Singapore to examine what fair and just pricing might look like from a Confucian perspective. This contribution reminds us of the central importance of professional values in all that we do, while also recognizing that economics also form part of the bigger picture.

In the final two original articles in this issue, the contributors concentrate directly on the current COVID-19 crisis. Ni et al. (2020) take us right back to the putative geographical source of the pandemic - Wuhan - where two case studies are examined to unpack the role and deeper meaning of the value of reciprocity in the times of COVID-19. Analysis is provided of social media and video blogs of professionals and citizens who were asked by authority figures to undertake exceptional personal measures - such as head-shaving - to address shortages in PPE. The findings are used to inform quarantine principles that are fitfor-purposes in the current pandemic, as well as to enrich our understandings of reciprocity in an increasingly connected world. Finally, in an article on which I am a co-author, Frowde et al. (2020) offer commentary on the human rights implications of governmental responses to COVID-19, but with something of a twist. Whereas there are extensive (and often well-grounded) concerns that active measures such as quarantine and lockdown can pose threats to citizens' rights, we argue the counter-perspective that governmental inaction - as demonstrated by the woeful example of the UK government's response to COVID-19 - can equally undermine human rights, potentially on a much longer timeframe, as failure after failure shows only too well that an unplanned response is an unethical response beyond justification or defence.

As indicated in the September editorial, our Call for Papers on ethical dimensions of COVID-19 has been very successful, and we are delighted to present here the latest cohort of contributions. As also indicated previously, many of these now seek to capture and reflect country-by-country responses to the pandemic, and we anticipate the value of a trenchant comparative analysis in due course. For now, our readers will find contributions from an intriguing range of countries, including India from Arunachalam and Halwai (2020), Bangladesh from Siraj et al. (2020), and Pakistan from Khalid and Ali (2020). We are particularly heartened that this last contribution enriches our Student Voices section of the journal-we encourage more students to submit to the journal and we guarantee supportive feedback in return.

Our other contributions in the Perspectives section focus on particular aspects of COVID-19, and in doing so they bring us back full circle to the starting point of this editorial: the pandemic has writ large stubborn social injustices and has made them worse. Persons who are already poor, disenfranchised, and suffering from long-term conditions, including those affecting mental health, invariably fair far worse under the circumstances of the current crisis. Thus, Cheung and Ip (2020) examine public mental health ethics and the disproportionate effects that lockdown have on persons living with mental ill-health. Salutary lessons arise as a result. Linking back to themes of scarce resources and human rights, Chen and McNamara (2020) examine triage arrangements and the risks associated with relying on quality of life assessments in medical decisionmaking during a pandemic. This is all the more important as the realities of 'long COVID' become clearer, and it is likely that more persons will have to live with some 
form of chronic disability even if they survive infection with COVID-19. On the questions of poverty and social injustice, Timmermann (2020) advocates for an increased role for engagement exercises with long-term economically disenfranchised groups in society, who for too long have not so much been 'hard-to-reach' but more accurately 'easy-to-ignore'. This approach holds the promise of more informed lessons for policymakers in designing more just responses to COVID-19.

Our final two contributions are connected by the concept of care. From Malaysia, Chong et al. (2020) consider the experiences of trying to deliver paediatric palliative care in circumstances where close contact between parents and children is difficult or impossible, and at a time when the imminence of death becomes an imperative to make every moment count. To complete our circle of contributions for this issue, Dine (2020) argues for an holistic and interdisciplinary approach to dealing with COVID-19 that attempts to capture the 'sameness' of humanity, as well as the duties that we owe to each other (while having our own rights duly respected). This leads us both to question who is truly vulnerable at this time, and also what do we owe to our fellow citizens. Dine argues, as a minimum, that this analysis supports mask-wearing during a pandemic - both as a preventative measure among a panoply of responses that are required, as well as a measure of respect for each other as we face an unprecedented crisis together.

\section{References}

Arunachalam, Meghna Ann, and Aarti Halwai. 2020. An analysis of the ethics of lockdown in India. Asian Bioethics Review 12 (4). https://doi.org/10.1007/s41649-020-00133-3.

Chen, Bo, and Donna Marie McNamara. 2020. Disability discrimination, medical rationing and COVID-19. Asian Bioethics Review 12 (4). https://doi.org/10.1007/s41649-020-00147-x.

Cheung, Daisy, and Eric C. Ip. 2020. COVID-19 lockdowns: A public mental health ethics perspective. Asian Bioethics Review 12 (4). https://doi.org/10.1007/s41649-020-00144-0.

Chong, Lee Ai, Erwin J. Khoo, Azanna Ahmad Kamar, and Hui Siu Tan. 2020. Paediatric palliative care during COVID-19 pandemic: A Malaysian perspective. Asian Bioethics Review 12 (4). https://doi.org/10. 1007/s41649-020-00142-2.

Dine, Charles Biradzem. 2020. Socio-ethical dimensions of COVID-19 prevention mechanism-The triumph of care ethics. Asian Bioethics Review 12 (4). https://doi.org/10.1007/s41649-020-00143-1.

Frowde, Rhiannon, Edward S. Dove, and Graeme T. Laurie. 2020. Fail to prepare and you prepare to fail: The human rights consequences of the UK Government's inaction during the COVID-19 pandemic. Asian Bioethics Review 12 (4). https://doi.org/10.1007/s41649-020-00151-1.

Khalid, Atiqa, and Sana Ali. 2020. COVID-19 and its challenges for the healthcare system in Pakistan. Asian Bioethics Review 12 (4). https://doi.org/10.1007/s41649-020-00139-x.

Ni, Yanping, Morris Fabbri, Chi Zhang, and Kearsley A. Stewart. 2020. Reciprocity in quarantine: observations from Wuhan's COVID-19 digital landscapes. Asian Bioethics Review 12 (4). https://doi.org/10. 1007/s41649-020-00150-2.

Ooi, Kanny. 2020. The pitfalls of overtreatment: Why more care is not necessarily beneficial. Asian Bioethics Review 12 (4). https://doi.org/10.1007/s41649-020-00145-z.

Siraj, Md. Sanwar, Rebecca Susan Dewey, and A.S.M. Firoz Ul Hassan. 2020. A perspective on COVID-19 in Bangladesh. Asian Bioethics Review 12 (4). https://doi.org/10.1007/s41649-020-00149-9.

Than, Mo Mo, Hein Htike, and Henry J. Silverman. 2020. Knowledge, awareness, attitudes and practices towards research ethics and research ethics committees among Myanmar postgraduate students. Asian Bioethics Review 12 (4). https://doi.org/10.1007/s41649-020-00148-w.

Timmermann, Cristian. 2020. Epistemic ignorance, poverty and the COVID-19 pandemic. Asian Bioethics Review 12 (4). https://doi.org/10.1007/s41649-020-00140-4. 
Wong, Gabriel Hong Zhe. 2020. Ethical pricing: A Confucian perspective. Asian Bioethics Review 12 (4). https://doi.org/10.1007/s41649-020-00146-y.

Publisher's Note Springer Nature remains neutral with regard to jurisdictional claims in published maps and institutional affiliations. 